\title{
GENERAL SOLUTIONS OF EQUATIONS OF SOME GEOPHYSICAL IMPORTANCE
}

\author{
By H. Takeuchi
}

\begin{abstract}
General solutions are obtained in rectangular, circular cylindrical, and spherical coordinates for the equations of motion of a homogeneous isotropic elastic body (in $\$ 2$ ), the equations of the corresponding statical deformations $(\$ 3)$, the equations of motion of an incompressible viscous fluid $(\$ 4)$, the equations of the corresponding stationary motion ( $\$ 5$ ), and Maxwell's equations for a homogeneous isotropic conductor $(\$ 6)$.
\end{abstract}

\$1. In studying the internal constitution of the earth we often make use of the theory of elasticity, the mechanics of a viscous fluid, and electromagnetic theory. Elastic wave propagations within the earth, and statical deformations of the earth by surface load, may be cited as examples of applications of the theory of elasticity. Crustal deformations in Scandinavia after the disappearance of the ice sheet, and the problem of convection currents within the earth, are discussed with use of the mechanics of a viscous fluid. Electromagnetic induction in the earth's mantle, and the dynamo theory of the earth's magnetic field, supply examples of applications of electromagnetic theory. All these problems have hitherto been studied more or less independently. From the mathematical point of view, however, there is almost no difference among them. It is one of the purposes of the present paper to make this point clear. In discussing the problems mentioned above, we sometimes make use of circular cylindrical and spherical coördinates rather than rectangular coördinates. Usually, in order to obtain solutions in spherical coördinates, for example, we at first transform the fundamental equations into spherical coördinates and then solve them. In this way, however, the symmetry among $x, y$, and $z$ in the equations are lost and an awkwardness occurs. In order to avoid this we shall use in the present paper rectangular coördinates as late as possible. As is seen below, this principle works well. Thus all we need in the following analysis is solutions of scalar wave equation and expressions of grad and rot in respective coördinates such as are found in any textbook in mathematical physics. Since the following analysis is as simple as possible, it should be useful to students. To research workers in such boundary regions as magnetohydrodynamics or magnetoelasticity it may give a clearer insight into their studies.

$\S 2$. Equations of motion of homogeneous and isotropic solids are given by

$$
\rho \frac{\partial^{2} U}{\partial t^{2}}=(\lambda+\mu) \operatorname{grad} \operatorname{div} U+\mu \nabla^{2} U
$$

where $U$ is the displacement vector, the $(x, y, z)$ components of which are

$$
U=(u, v, w)
$$

Manuscript received for publication February 3, 1959. The author, now at the Seismological Laboratory in Pasadena, is on leave from the Geophysical Institute, Tokyo University. 
and $\nabla^{2} U$ is a vector defined by

$$
\nabla^{2} U=\operatorname{grad} \operatorname{div} U-\operatorname{rot} \operatorname{rot} U
$$

The $\xi$ component, say, in general curvilinear coördinates $(\xi, \eta, \zeta)$ is different from that obtained by applying formally the operation $\nabla^{2}=$ div grad to the $\xi$ component of $U$. It is only in rectangular coördinates that the foregoing is true. Thus, we have, for example

$$
\left(\nabla^{2} U\right)_{x}=\left(\frac{\partial^{2}}{\partial x^{2}}+\frac{\partial^{2}}{\partial y^{2}}+\frac{\partial^{2}}{\partial z^{2}}\right) u
$$

In order to make full use of this convenient formula, we shall make the following analysis in rectangular coördinates as late as possible.

For $U$ in (2.1), we assume

$$
\begin{aligned}
& U=U_{1}+U_{2}+U_{3} \\
& U_{1}=\operatorname{grad} \phi \\
& U_{2}=\operatorname{rot} A \\
& U_{3}=\operatorname{rot} U_{2}
\end{aligned}
$$

where $\phi$ is a scalar function and $A$ is a vector function to be determined. By the well-known vector formulae we have

$$
\operatorname{rot} U_{1}=\operatorname{div} U_{2}=\operatorname{div} U_{3}=0
$$

Putting (2.6) into (2.1) will give the following equation for $\phi$

$$
\rho \frac{\partial^{2} \phi}{\partial t^{2}}=(\lambda+2 \mu) \nabla^{2} \phi
$$

where $\nabla^{2}$ means the operation div grad. Making use of (2.9) and (2.1), we get the following equation for $U_{2}$.

$$
\rho \frac{\partial^{2} U_{2}}{\partial t^{2}}=\mu \nabla^{2} U_{2}
$$

It can easily be shown that $U_{3}$ is a solution of (2.1), or (2.11), if $U_{2}$ is. As $A$ in (2.7) the following two forms are usually used.

$$
\begin{aligned}
& \left(A_{x}, A_{y}, A_{z}\right)=(0,0,1) \psi \\
& \left(A_{x}, A_{y}, A_{z}\right)=(x, y, z) \psi
\end{aligned}
$$


where $\psi$ is a scalar function to be determined. Putting (2.13) into (2.7) and the result thus obtained into (2.11) will give

$$
\left(\begin{array}{l}
z \frac{\partial}{\partial y}-y \frac{\partial}{\partial z} \\
x \frac{\partial}{\partial z}-z \frac{\partial}{\partial x} \\
y \frac{\partial}{\partial x}-x \frac{\partial}{\partial y}
\end{array}\right)\left(\rho \frac{\partial^{2} \psi}{\partial t^{2}}-\mu \nabla^{2} \psi\right)=0
$$

In order that the foregoing be true, we must have

$$
\rho \frac{\partial^{2} \psi}{\partial t^{2}}=\mu \nabla^{2} \psi
$$

From $A$ in (2.12) we get also (2.14). In short, from $\phi$ and $\psi$ satisfying (2.10) and (2.14), respectively, we get $(2.6),(2.12)$ or $(2.13) \rightarrow(2.7)$ and $(2.8)$ as the solution of $(2.1)$.

(2.10) and (2.14) are the familiar scalar wave equations. Their solutions in rectangular, circular cylindrical, and spherical coördinates are as follows.

Rectangular coördinates $(x, y, z)$ :

$$
\phi=e^{i(p t+l x+m y+n z)}
$$

where

$$
l^{2}+m^{2}+n^{2}=h^{2}=\frac{\rho p^{2}}{\lambda+2 \mu}
$$

Circular cylindrical coördinates $(r, \theta, z)$ :

$$
\phi=e^{\imath(p t+m \theta+n z)} C_{m}(l r)
$$

where

$$
l^{2}+n^{2}=h^{2}
$$

and $C_{m}(l r)$ is a cylindrical function.

Spherical coördinates $(r, \theta, \varphi)$ :

$$
\phi=e^{i\left(p t+m_{f}\right)} P_{n}^{m}(\theta) r^{-\frac{1}{2}} C_{n+\frac{1}{2}}(h r)
$$

where $P_{n}^{m}(\theta)$ is a Legendre and $C_{n+\frac{1}{2}}(h r)$ is a cylindrical function.

In the foregoing we showed solutions $\phi$ satisfying (2.10). Solutions $\psi$ satisfying (2.14) are obtained by replacing $h^{2}$ by $k^{2}=\left(\rho p^{2}\right) / \mu$.

Having thus got $\phi$ and $\psi$, we shall now get $U_{1}, U_{2}$, and $U_{3}$ in the respective coordinates. 
Rectangular coördinates:

Making use of the expression of grad in rectangular coördinates, we have

$$
U_{1}: \quad u_{x}=\frac{\partial \phi}{\partial x}, \quad u_{y}=\frac{\partial \phi}{\partial y}, \quad u_{z}=\frac{\partial \phi}{\partial z}
$$

As $A$ in the present case we take (2.12). The expression of rot in rectangular coördinates will give

$$
\begin{aligned}
& U_{2}: \quad u_{x}=\frac{\partial \psi}{\partial y}, \quad u_{y}=-\frac{\partial \psi}{\partial x}, \quad u_{z}=0 \\
& U_{3}: \quad u_{x}=\frac{\partial^{2} \psi}{\partial x \partial z}, \quad u_{y}=\frac{\partial^{2} \psi}{\partial y \partial z}, \quad u_{z}=-\left(\frac{\partial^{2}}{\partial x^{2}}+\frac{\partial^{2}}{\partial y^{2}}\right) \psi
\end{aligned}
$$

Circular cylindrical coördinates:

The expression of grad in circular cylindrical coördinates will give

$$
U_{1}: \quad u_{r}=\frac{\partial \phi}{\partial r}, \quad u_{\theta}=\frac{\partial \phi}{r \partial \theta}, \quad u_{z}=\frac{\partial \phi}{\partial z}
$$

As $A$ in the present case we take (2.12), expression for which in circular cylindrical coördinates is

$$
A: \quad A_{r}=A_{\theta}=0, \quad A_{z}=\psi
$$

Making use of (2.22) and the expression of rot in circular cylindrical coördinates, we get

$$
\begin{gathered}
U_{2}: \quad u_{r}=\frac{\partial \psi}{r \partial \theta}, \quad u_{\theta}=-\frac{\partial \psi}{\partial r}, \quad u_{z}=0 \\
U_{3}: \quad u_{r}=\frac{\partial^{2} \psi}{\partial r \partial z}, \quad u_{\theta}=\frac{\partial^{2} \psi}{r \partial \theta \partial z}, \\
u_{z}=-\left(\frac{\partial^{2}}{\partial r^{2}}+\frac{1}{r} \frac{\partial}{\partial r}+\frac{1}{r^{2}} \frac{\partial^{2}}{\partial \theta^{2}}\right) \psi
\end{gathered}
$$

Spherical coördinates:

The expression of grad in spherical coördinates will give

$$
U_{1}: \quad u_{r}=\frac{\partial \phi}{\partial r}, \quad u_{\theta}=\frac{\partial \phi}{r \partial \theta}, \quad u_{\varphi}=\frac{\partial \phi}{r \sin \theta \partial \varphi}
$$

As $A$ in the present case we use (2.13), the expression for which in spherical coordinates is

$$
A: \quad A_{r}=r \psi, \quad A_{\theta}=A_{\varphi}=0
$$


Making use of (2.26) and the expression of rot in spherical coördinates, we get

$$
\begin{aligned}
U_{2}: \quad u_{r} & =0, \quad u_{\theta}=\frac{\partial \psi}{\sin \theta \partial \varphi}, \quad u_{\varphi}=-\frac{\partial \psi}{\partial \theta} \\
U_{3}: \quad u_{r} & =-\frac{1}{r \sin \theta}\left\{\frac{\partial}{\partial \theta}\left(\sin \theta \frac{\partial \psi}{\partial \theta}\right)+\frac{1}{\sin \theta} \frac{\partial^{2} \psi}{\partial p^{2}}\right\}, \\
u_{\theta} & =\frac{\partial^{2}(r \psi)}{r \partial r \partial \theta}, \quad u_{\varphi}=\frac{\partial^{2}(r \psi)}{r \sin \theta \partial r \partial \varphi}
\end{aligned}
$$

The results in the present section have already been obtained by K. Sezawa (1927) in a somewhat complicated way.

\$. General solutions for statical deformations of homogeneous and isotropic solids can be obtained by putting $\partial / \partial t \sim p=0$ in the results in the last section. Thus $U_{1}$ and $U_{2}$ for statical deformations can be obtained by putting

Rectangular coördinates:

$$
\phi=\psi=e^{i(l x+m y)+n z}, \quad l^{2}+m^{2}=n^{2}
$$

Circular cylindrical coördinates:

$$
\phi=\psi=e^{i m \theta+l z} C_{m}(l r)
$$

Spherical coördinates:

$$
\phi=\psi=r^{n}\left(\text { or } r^{-n-1}\right) e^{i m \varphi} P_{n}^{m}(\theta)
$$

into (2.18), (2.19); (2.21), (2.23); and (2.25), (2.27), respectively. $\phi$ and $\psi$ in (3.1)(3.3) are obtained by putting $p=0$ in (2.15)-(2.17) and are solutions of the Laplace equations in respective coördinates. The $r$ part in (3.3), that is, $r^{n}$ or $r^{-n-1}$, is the first term of the series expansion

$$
\jmath_{n}(p) \sim r^{n}\left\{1-\frac{p^{2}}{2(2 n+3)}+\cdots\right\}
$$

or

$$
n_{n}(p) \sim r^{-n-1}\left\{1+\frac{p^{2}}{2(2 n-1)}+\cdots\right\}
$$

for the $r$ part

$$
j_{n}(p)=\sqrt{\frac{\pi}{2 p}} J_{n+\frac{1}{2}}(p)
$$

or

$$
n_{n}(p)=\sqrt{\frac{\pi}{2 p}} N_{n+\frac{1}{2}}(p)=(-1)^{n+1} j_{-n-1}(p)
$$

where $p=h r$ or $k r$. 
In statical deformations, $U_{1}$ and $U_{3}$ are not independent of each other. In order to make this point clear and to get a new independent solution in circular cylindrical coördinates, taking (2.16) into consideration, we shall put

$$
\begin{aligned}
& \phi=e^{i(p t+m \theta+n z)} C_{m}(l r), \\
& \psi=e^{i\left(p t+n \theta+n^{\prime} z\right)} C_{m}(l r), \\
& l^{2}+n^{2}=h^{2}=\frac{p p^{2}}{\lambda+2 \mu}, \\
& l^{2}+n^{\prime 2}=k^{2}=\frac{\rho p^{2}}{\mu}
\end{aligned}
$$

in (2.21) and (2.24) and calculate

$$
U_{3}^{\prime} \equiv U_{1}-\frac{U_{3}}{i n}
$$

Putting $p=0$ in (3.8) will give $U_{3}^{\prime} \equiv 0$. This shows that $U_{1}$ and $U_{3}$ are not independent of each other in the present case. A new independent solution in such a case is given by the first term in the series expansion of $U_{s}^{\prime}$ with respect to $p^{2}$. From

$$
n^{2}=n^{2}+\left(k^{2}-h^{2}\right)
$$

we get for $p \rightarrow 0$

$$
n^{\prime}=n+\delta, \quad \delta=\frac{k^{2}}{2 n}\left(1-\frac{h^{2}}{k^{2}}\right)
$$

The first order term of $U_{3}^{\prime}$ with respect to $\delta \sim p^{2}$ will give

$$
\begin{aligned}
U_{3}^{\prime}: \quad u_{r} & =\frac{d C_{m}(l r)}{d r} e^{i(m \theta+n z)}\left(1-e^{i \hat{\delta} z}\right) \\
& =-\frac{d C_{m}(l r)}{d r} e^{i(m \theta+n z)} i \delta z \\
u_{\theta} & =-\frac{C_{m}(l r)}{r} \frac{d}{d \theta}\left(e^{i m \theta}\right) e^{i n z} i \delta z
\end{aligned}
$$

Special care must be taken in the calculation of the $z$ component of $U_{3}^{\prime}$. At first, the $z$ component of $U_{3}$ is given by

$$
U_{3}: \quad u_{z}=\left(\frac{\partial^{2}}{\partial z^{2}}+k^{2}\right) \psi
$$

where

$$
k^{2}=\frac{2 n \delta}{\left(1-h^{2} / k^{2}\right)}=\frac{2 n(\lambda+2 \mu)}{\lambda+\mu} \delta
$$


is a small quantity of the same order as $\delta$. Thus we get

$$
U_{3}^{\prime}: \quad u_{z}=C_{m}(l r) e^{\imath(m \theta+n z)} i \delta\left(-1-i n z+\frac{2}{1-h^{2} / k^{2}}\right)
$$

In short, we have

$$
\begin{aligned}
U_{3}^{\prime}: \quad u_{r} & =-\frac{d C_{m}(l r)}{d r} e^{i m \theta+l z} z \\
u_{\theta} & =-\frac{1}{r} C_{m}(l r) \frac{d}{d \theta}\left(e^{i m \theta}\right) e^{l z} z \\
u_{z} & =C_{m}(l r) e^{i m \theta+l z}\left(-1-l z+\frac{2}{1-h^{2} / k^{2}}\right)
\end{aligned}
$$

$l^{2}+n^{2}=0$ being taken into account in the above. Equations (3.2), (2.21), (2.23), and (3.15) agree with the results obtained by K. Terazawa (1916).

In a similar way, we get in rectangular coördinates

$$
\begin{aligned}
U_{3}^{\prime}: \quad u_{x} & =-\frac{\partial}{\partial x}\left\{e^{i(l x+m y)+n z}\right\} z \\
u_{y} & =-\frac{\partial}{\partial y}\left\{e^{i(l x+m y)+n z}\right\} z \\
u_{z} & =e^{i(l x+m y)+n z}\left(-1-n z+\frac{2}{1-h^{2} / k^{2}}\right) \\
l^{2} & +m^{2}=n^{2}
\end{aligned}
$$

A new independent solution in spherical coördinates is given by the first order term of the series expansion of

$$
U_{3}^{\prime} \equiv U_{1}-\frac{U_{3}}{n+1}
$$

with respect to $h^{2}, k^{2} \sim p^{2} \rightarrow 0$. In calculating (3.17), we use (2.25) (2.28) with (3.4) and (3.5). Thus we get

$$
\begin{aligned}
U_{3}^{\prime}: \quad u_{r}=e^{i m \varphi} P_{n}^{m}(\theta) & {\left[\frac{d}{d r}\left\{r^{n}-\frac{h^{2} r^{n+2}}{2(2 n+3)}\right\}\right.} \\
& \left.\quad-\frac{1}{n+1} \frac{d^{2}}{d r^{2}}\left\{r^{n+1}-\frac{k^{2} r^{n+3}}{2(2 n+3)}\right\}-\frac{k^{2} r^{n+1}}{n+1}\right] \\
= & e^{i m \varphi} P_{n}^{m}(\theta) \frac{k^{2} r^{n+1}}{2(2 n+3)}\left\{-\frac{h^{2}}{k^{2}}(n+2)\right.
\end{aligned}
$$




$$
\begin{gathered}
\left.\quad+\frac{(n+3)(n+2)}{n+1}-\frac{2(2 n+3)}{n+1}\right\}, \\
u_{\theta}=\frac{\partial}{r \partial \theta}\left\{e^{i m \varphi} P_{n}^{m}(\theta)\right\}\left[r^{n}\left\{1-\frac{h^{2} r^{2}}{2(2 n+3)}\right\}\right. \\
\left.\quad-\frac{1}{n+1} \frac{d}{d r}\left\{r^{n+1}-\frac{k^{2} r^{n+3}}{2(2 n+3)}\right\}\right] \\
=\frac{\partial}{r \partial \theta}\left\{e^{i m \varphi} P_{n}^{m}(\theta)\right\} \frac{k^{2} r^{n+2}}{2(2 n+3)}\left(-\frac{h^{2}}{k^{2}}+\frac{n+3}{n+1}\right) \\
u_{\rho}=\frac{\partial}{r \sin \theta \partial \varphi}\left\{e^{i m \varphi} P_{n}^{m}(\theta)\right\} \frac{k^{2} r^{n+2}}{2(2 n+3)}\left(-\frac{h^{2}}{k^{2}}+\frac{n+3}{n+1}\right)
\end{gathered}
$$

In (3.18), we make use of

$$
U_{3}: \quad u_{r}=\left(\frac{\partial^{2}}{\partial r^{2}}+k^{2}\right)(r \psi)
$$

Putting $k^{2}=0$ in (3.18) will give $U_{3}{ }^{\prime} \equiv 0$, which shows that $U_{1}$ and $U_{3}$ are not independent of each other. $U_{3}^{\prime}$ in (3.18) is obtained by using (3.4). One more independent solution is obtained using (3.5) instead of (3.4). We can get this solution by replacing formally $n$ in (3.18) by $-(n-1)$, the $n$ in the expression of $P_{n}^{m}(\theta)$ being an exception to this replacement.

$\S 4$. Equations of slow motion of an incompressible viscous fluid are given by

$$
\begin{gathered}
\operatorname{div} U=0 \\
\frac{\partial U}{\partial t}=-\operatorname{grad}\left(q+\frac{p}{\rho}\right)+\frac{\mu}{\rho} \nabla^{2} U
\end{gathered}
$$

where $U$ is fluid velocity vector, $p$ pressure, $\rho$ density, and $\mu$ coefficient of viscosity, force $F$ being assumed to be derivable from a potential $q$ by

$$
F=-\operatorname{grad} q
$$

Taking div of (4.2) and using (4.1), we get

$$
\nabla^{2}\left(q+\frac{p}{\rho}\right)=0
$$

For $U$ in (4.2), we assume

$$
\begin{gathered}
U=U_{1}+U_{2}+U_{3} \\
U_{1}=-\int \operatorname{grad}\left(q+\frac{p}{\rho}\right) d t
\end{gathered}
$$


By (4.4)

$$
\operatorname{div} U_{1}=0
$$

thus satisfying (4.1). Putting (4.5) into (4.2) and taking (4.6) and (4.7) into consideration will give the following equations for $U_{2}$ and $U_{3}$ :

$$
\frac{\partial U}{\partial t}=\frac{\mu}{\rho} \nabla^{2} U, \quad \operatorname{div} U=0
$$

Solutions of (4.4) are the same as $\phi$ and $\psi$ in (3.1)-(3.3). In calculating $U_{1}$ by (4.6) we may refer to $(2.18),(2.21)$, and (2.25). (4.8) is of the same form as (2.11). Thus we have $U_{2}$ and $U_{3}$ in $(2.19),(2.20) ;(2.23),(2.24)$, and (2.27), (2.28), except that $\psi$ satisfies

$$
\frac{\partial \psi}{\partial t}=\frac{\mu}{\rho} \nabla^{2} \psi
$$

Assuming that $\psi \propto e^{-\alpha t}$ will give

$$
\left(\nabla^{2}+k^{2}\right) \psi=0, \quad k^{2}=\frac{\rho \alpha}{\mu}
$$

Thus we see that $\psi$ in the present case is given by (2.15) to (2.17) with $k^{2}=\rho \alpha / \mu$.

$\S 5$. When the motion in the last section is stationary and $\partial / \partial t \sim \alpha=0$, we have the same $U_{1}$ and $U_{2}$ as in section 3 . For a finite $U_{1}$ we have by (4.6)

$$
q+\frac{p}{\rho} \sim \alpha=0
$$

$U_{1}$ and $U_{3}$ in the present case are not independent of each other as in section $3 . \mathrm{A}$ new independent solution $U_{3}$ is obtained by putting

$$
h^{2}=0, \quad k^{2}=\frac{\rho \alpha}{\mu} \rightarrow 0
$$

into (3.15), (3.16), and (3.18). This will be understood by comparing (4.6) and (4.4) with (2.6), (2.10), (2.15)-(2.17). The foregoing results in circular cylindrical coordinates agree with those obtained by Haskell $(1935,1936)$.

\$6. Maxwell's equations for a homogeneous isotropic conductor are given by

$$
\begin{aligned}
& \operatorname{div} \mathbf{E}=0 \\
& \operatorname{div} H=0 \\
& \operatorname{rot} \mathbf{E}=-\frac{\mu}{c} \frac{\partial H}{\partial t} \\
& \operatorname{rot} H=\left(\frac{4 \pi \sigma}{c}+\frac{\epsilon}{c} \frac{\partial}{\partial t}\right) \mathrm{E}
\end{aligned}
$$


where $c$ is the light velocity, $\sigma$ electric conductivity, $\epsilon$ dielectric constant, and $\mu$ permeability. $\sigma, \epsilon, \mathrm{E}$ and $\mu, H$ are expressed in e.s.u. and e.m.u., respectively. Taking rot of (6.3) and using (2.3), (6.1) and (6.4), we have

$$
\begin{aligned}
& \frac{\mu}{c^{2}} \frac{\partial}{\partial t}\left(4 \pi \sigma+\epsilon \frac{\partial}{\partial t}\right) \mathbf{E}=\nabla^{2} \mathbf{E} \\
& \operatorname{div} \mathbf{E}=0
\end{aligned}
$$

Similarly, we have

$$
\begin{aligned}
& \frac{\mu}{c^{2}} \frac{\partial}{\partial t}\left(4 \pi \sigma+\epsilon \frac{\partial}{\partial t}\right) H=\nabla^{2} H \\
& \operatorname{div} H=0
\end{aligned}
$$

As (6.5) is of the same form as in (2.9) and (2.11), we shall put

$$
\begin{aligned}
& \mathrm{E}=\mathrm{E}_{1}+\mathrm{E}_{2} \\
& \mathrm{E}_{1}=\operatorname{rot} A \\
& \mathrm{E}_{2}=\operatorname{rot} \mathrm{E}_{1} \\
& \left(A_{x}, A_{y}, A_{z}\right)=(0,0,1) \psi
\end{aligned}
$$

or

$$
\left(A_{x}, A_{y}, A_{z}\right)=(x, y, z) \psi
$$

Putting the above equations into (6.5) will give

$$
\frac{\partial}{\partial t}\left(\frac{\partial}{\partial t}+\frac{4 \pi \sigma}{\epsilon}\right) \psi=\frac{\sigma^{2}}{\mu \epsilon} \nabla^{2} \psi
$$

which, on assuming

$$
\psi \propto \alpha e^{i p t}
$$

is reduced to

$$
\left(\nabla^{2}+k^{2}\right) \psi=0, \quad k^{2}=\frac{\epsilon \mu}{c^{2}}\left(p^{2}-\frac{4 \pi \sigma p}{\epsilon} i\right)
$$

Thus we get $\mathrm{E}_{1}$ and $\mathrm{E}_{2}$ by putting (2.15) to (2.17) with

$$
k^{2}=\frac{\epsilon \mu}{c^{2}}\left(p^{2}-\frac{4 \pi \sigma p}{\epsilon} i\right)
$$


into (2.19), (2.23), (2.27) and (2.20), (2.24), (2.28), respectively. $H_{1}$ and $H_{2}$ corresponding to the above $\mathbf{E}_{1}$ and $\mathbf{E}_{2}$ are given by (6.3), (6.5), (6.9), and (2.3) as follows.

$$
\begin{aligned}
& H_{1}=\frac{i c}{\mu p} \operatorname{rot} \mathrm{E}_{1}=\frac{i c}{\mu p} \mathrm{E}_{2}, \\
& H_{2}=\frac{i c}{\mu p} \operatorname{rot} \mathrm{E}_{2}=\frac{i c k^{2}}{\mu p} \mathrm{E}_{1}
\end{aligned}
$$

The results in the present section agree with those in Stratton's textbook (1941).

\section{Acknowledgments}

This study was carried out at the Seismological Laboratory of the California Institute of Technology. The author wishes to thank Dr. F. Press for the opportunity to visit there and for valuable suggestions throughout the study, to Mr. J. Nordquist for reading through the manuscript, and to the Alfred P. Sloan Foundation for financial support.

Haskell, N. A.

\section{REFERENCES}

1935. "The Motion of a Viscous Fluid under a Surface Load," Physics, 6: 265-269.

1936. "The Motion of a Viscous Fluid under a Surface Load," Physics, 7: 56-61.

Sezawa, K.

1927. "Dilatational and Distortional Waves Generated from a Cylindrical or a Spherical Origin," Bull. Earthq. Res. Inst., 2: 13-20.

Stratton, J. A.

1941. Electromagnetic Theory (New York: McGraw-Hill), p. 360 and 414.

Terazawa, K.

1916. "On the Elastic Equilibrium of a Semi-Infinite Solid under Given Boundary Conditions, with Some Applications," Jour. Coll. Sci. Imp. Univ. Tokyo, Vol. 37, Art. 7 (64 pp.).

Seismological Laboratory,

California Institute of Technology,

Pasadena, Califfornia.

(Division of the Geological Sciences, Contribution no. 916.) 